\title{
Human health no-effect levels of TiO2 nanoparticles as a function of their primary size
}

Laurent, Alexis; Harkema, Jack; Andersen, Elisabeth Wreford; Owsianiak, Mikolaj; Blikra Vea, Eldbjørg; Jolliet, Olivier

Published in:

Journal of Nanoparticle Research

Link to article, DOI:

10.1007/s11051-017-3816-8

Publication date:

2017

Document Version

Peer reviewed version

Link back to DTU Orbit

Citation $(A P A)$ :

Laurent, A., Harkema, J., Andersen, E. W., Owsianiak, M., Blikra Vea, E., \& Jolliet, O. (2017). Human health noeffect levels of TiO2 nanoparticles as a function of their primary size. Journal of Nanoparticle Research, 19(130). https://doi.org/10.1007/s11051-017-3816-8

\section{General rights}

Copyright and moral rights for the publications made accessible in the public portal are retained by the authors and/or other copyright owners and it is a condition of accessing publications that users recognise and abide by the legal requirements associated with these rights.

- Users may download and print one copy of any publication from the public portal for the purpose of private study or research.

- You may not further distribute the material or use it for any profit-making activity or commercial gain

- You may freely distribute the URL identifying the publication in the public portal 
2 nanoparticles as a function of their primary size

Alexis Laurent ${ }^{1} *$, Jack R. Harkema ${ }^{2}$, Elisabeth W. Andersen ${ }^{3}$,

$7 \quad{ }^{1}$ Division for Quantitative Sustainability Assessment, Department of Management Engineering,

8 Technical University of Denmark, 2800 Kgs. Lyngby, Denmark

$9{ }^{2}$ Department of Pathobiology and Diagnostic Investigation, College of Veterinary Medicine,

10 Michigan State University, East Lansing, Michigan, U.S.A.

$11{ }^{3}$ Statistics and Data Analysis Section, Department of Applied Mathematics and Computer

12 Science, Technical University of Denmark, 2800 Kgs. Lyngby, Denmark

$13{ }^{4}$ Department of Environmental Health Sciences, School of Public Health, University of

14 Michigan, Ann Arbor, Michigan, U.S.A.

15

16

17 * To whom correspondence should be addressed; e-mail: alau@dtu.dk, Tel.: (+45) 45254423 
Laurent A., Harkema J., Andersen E. W., Owsianiak M., Vea E. B., Jolliet O., 2017. Human health no-effect levels of $\mathrm{TiO}_{2}$ nanoparticles as a function of their primary size. Journal of Nanoparticle Research 19, 130.

DOI:10.1007/s11051-017-3816-8.

\section{Abstract}

21 As engineered nanomaterials are increasingly introduced on the market into a broad range of

22 commodities or nanoproducts, there is a need for operational, reliable tool, enabling to

23 consistently assess the risks and impacts associated with the releases of nanoparticles. The lack

24 of a developed metric that accurately represents their toxic effects while capturing the influence

25 of the most relevant physicochemical properties is one of the major impediments. Here, we

26 investigate the relationships between the toxic responses of nano-sized and micro-sized particles

27 in in vivo toxicological studies and their physicochemical properties. Our results for $\mathrm{TiO}_{2}$

28 particles indicate statistically-significant associations between the primary particle size and their

29 toxicity responses for combined inhalation and ingestion exposure routes, although the numerical

30 values should be considered with care due to the inability to encompass influences from other

31 relevant physicochemical properties like surface coatings. These findings allow for expressing

32 mass-based adverse effect levels as a continuous function of the primary size of particles. This

33 meaningful, exploratory metric can thus be used for screening purposes and pave the way for

34 reaching adaptive, robust risk assessments of nanomaterials, e.g. for setting up consistent

35 threshold levels, as well as consistent life cycle assessments of nanoproducts. We provide

36 examples of such applications.

38 Keywords

39 Titanium dioxide, particle size, toxicity, nanotoxicology, risk assessment, life cycle assessment

\section{1. Introduction}


Laurent A., Harkema J., Andersen E. W., Owsianiak M., Vea E. B., Jolliet O., 2017. Human health no-effect levels of $\mathrm{TiO}_{2}$ nanoparticles as a function of their primary size. Journal of Nanoparticle Research 19, 130.

DOI:10.1007/s11051-017-3816-8.

The commercialization of engineered nanomaterials has dramatically increased over the past

43 years (Hendren et al., 2011; Keller et al. 2013; Mitrano et al., 2015). Simultaneously, the

44 potential releases of nanoparticles and their consequent risks and impacts along the life cycle of

45 nanoproducts (products embedding nanomaterials) have been raised in many studies (Grieger et

46 al. 2012; Maynard et al. 2006; Nel et al. 2006; Oberdörster 2010; Oberdörster et al. 2005;

47 SCENIHR 2009; Stone et al. 2010a; Wiesner et al. 2006). Several works have thus attempted to

48 perform human and ecological risk assessments of several nanomaterials, e.g. nano-scale

49 titanium dioxide (Christensen et al. 2011; US-EPA 2010; Warheit 2013). Likewise, a number of

50 studies have performed life cycle assessments of nanoproducts, quantifying the environmental

51 impacts from their manufacture, use and disposal stages (e.g. Walser et al. 2011). However, these

52 attempts do not gather sufficient robustness and reliability to allow for conclusive assessments of

53 the risks and impacts stemming from the released nanoparticles because of difficulties in

54 estimating their actual emissions and in identifying, tracking and evaluating the many parameters

55 influencing their fate, transport and toxicity (Aschberger et al. 2011; Jolliet et al. 2014;

56 Savolainen et al. 2010; Warheit 2013).

57 To support the evaluation of the health effects, a large number of toxicological studies have

58 been conducted (see review by Krug, 2014). Several reviews have been published over the years

59 to synthesize current knowledge and give overviews of the toxic effects of fine particles and/or

60 nanoparticles (e.g. see non-exhaustive list in Supplementary Methods; Krug, 2014). Very few of

61 these have performed comprehensive, quantitative analyses of the findings to identify possible

62 common patterns. Most works provide thorough snapshots of existing studies at a given time, but

63 limit their analyses to qualitative discussions. Among the most comprehensive ones, the study by

64 Krug (2014) has thus analyzed general trends observed over more than 10000 publications and 
Laurent A., Harkema J., Andersen E. W., Owsianiak M., Vea E. B., Jolliet O., 2017. Human health no-effect levels of $\mathrm{TiO}_{2}$ nanoparticles as a function of their primary size. Journal of Nanoparticle Research 19, 130.

DOI:10.1007/s11051-017-3816-8.

65 showed that, despite the sheer number of studies, a number of challenges still remains in their

66 interpretation, particularly due to a lack of comparability across studies and a widespread

67 omission of consistent characterization of the nanoparticles (Krug, 2014). The generally poor

68 reporting of physicochemical properties known to influence the toxicity of nanoparticles has

69 often been raised (e.g. Clark et al. 2012; Krug, 2014). Among the relevant physicochemical

70 properties, the primary particle size, shape, specific surface area, surface chemistry and

71 reactivity, composition, coating composition, crystallinity, charge, solubility and state of

72 agglomeration and aggregation have been flagged as the most important (e.g. Maynard and

73 Aitken 2007; MINChar 2008; Landsiedel et al. 2010; Oberdörster 2010; Stone et al. 2010a). The

74 primary particle size, one of the most studied properties, has been demonstrated to significantly

75 contribute to the toxic effects (Oberdörster et al. 2005). This relationship indicates that the mass

76 of particles alone cannot be a sufficient metric to characterize their toxic effects since the intake

77 (i.e. amount of nanoparticle entering the body) of a same mass of particles of different sizes may

78 result in different toxic effects (Oberdörster et al. 2005). To date, there is still a need to better

79 characterize the effects of nanoparticles on human health once they are inhaled or ingested as a

80 function of their physicochemical properties (Jolliet et al. 2014).

81 In this study, we propose a methodology to quantitatively investigate the relationships

82 between the non-carcinogenic effects of nano-sized and micro-sized particles and selected

83 physicochemical properties so that it can ultimately serve as support for risk assessment and life

84 cycle assessment of nanomaterials and nanoproducts. We focus on nano-scale titanium dioxide

$85\left(\mathrm{TiO}_{2}\right)$, which is among the mostly used nanomaterials on the market and one of the mostly

86 investigated in toxicological studies (Hendren et al., 2011; Keller et al. 2013; Mitrano et al.

87 2015). We specifically aim to (i) review the experimental settings and findings of all available in 
Laurent A., Harkema J., Andersen E. W., Owsianiak M., Vea E. B., Jolliet O., 2017. Human health no-effect levels of $\mathrm{TiO}_{2}$ nanoparticles as a function of their primary size. Journal of Nanoparticle Research 19, 130.

DOI:10.1007/s11051-017-3816-8.

88 vivo studies published on this material that met selection criteria with respect to exposure routes,

89 exposure time and observed toxic endpoints; (ii) analyze ways to investigate relationships

90 between non-carcinogenic effects of nanoparticles and selected physicochemical properties, (iii)

91 explore the derivation and application of no-observed adverse effect levels (NOAELs) for nano-

92 sized and micro-sized particles to be used in risk assessment and life cycle assessment.

\section{2. Methodology}

\section{2.1. Overview of the methodology}

96 The overall methodology consists of a 6-step approach, which includes (1) identification and

97 selection of in vivo studies, (2) characterisation of particles with respect to their reported

98 physicochemical properties, (3) expression of the doses into "intake doses" to allow comparisons

99 across exposure routes, (4) review of the displayed toxicity responses for each experiment using

100 information on the endpoints reflecting adverse effects resulting from exposure to the

101 nanoparticle, (5) statistical analyses of the relationships between the reported physicochemical

102 properties and the incidence or absence of adverse effects, and (6) extrapolations to human

103 equivalent doses. Each of these steps is succinctly described in the following subsections.

104 In the following, the term 'experiment' refers to a test on a given species exposed to a

105 specific type of particles (in terms of sizes, surface treatment and crystal form -see below section

106 on particle characterisation). An experiment may include several exposure levels (i.e. different

107 doses). The term 'study' refers to a set of experiments performed by the same research group,

108 and may include different particle types, exposure pathways and test animals. 
Laurent A., Harkema J., Andersen E. W., Owsianiak M., Vea E. B., Jolliet O., 2017. Human health no-effect levels of $\mathrm{TiO}_{2}$ nanoparticles as a function of their primary size. Journal of Nanoparticle Research 19, 130.

DOI:10.1007/s11051-017-3816-8.

\subsection{Identification, selection and classification of studies}

111 The identification of in vivo studies was done through literature search engine, and (see

112 Supplementary Methods) complemented by the cross-checking of citing and cited literature as

113 well as studies cited in review papers in the field of nanotoxicology. Complete documentation of

114 those steps is available in Supplementary Methods.

115 In vitro studies were disregarded because they relate to acute toxicity and methods to use

116 them for predicting chronic (i.e. long-term) in vivo toxicity are yet undeveloped (Oberdörster

117 2010). Ways of incorporating the large pool of data stemming from them should however be

118 better investigated (Oberdörster 2010; Krug, 2014). Out of the retrieved in vivo studies, filtering

119 criteria were applied to retain (i) studies with sufficiently long exposure durations, (ii) studies for

120 which the monitored toxic endpoints are comparable with other studies, (iii) studies, for which

121 reporting contains sufficient information for particle characterisation and analysis of the results,

122 (iv) studies addressing oral and inhalation exposure pathways, which are both considered the

123 most relevant for risk assessment and life cycle assessment applications. For the latter, because

124 no consensus currently exist on the correspondence between inhalation and intratracheal

125 instillation studies, the intratracheal instillation tests, in which the particles are directly

126 administered into the lower part of the respiratory tract of the animal under anaesthesia, were

127 disregarded in the current study (see, e.g. Aitken et al. 2009; Bakand et al. 2012; Driscoll et al.

128 1991, 2000; Warheit et al. 2005). However, further work should continue exploring the

129 comparability of the results in the large body of intratracheal instillation experiments (> 50

130 studies) with the findings from inhalation studies to bring additional data for interpretation

131 (Krug, 2014). 
Laurent A., Harkema J., Andersen E. W., Owsianiak M., Vea E. B., Jolliet O., 2017. Human health no-effect levels of $\mathrm{TiO}_{2}$ nanoparticles as a function of their primary size. Journal of Nanoparticle Research 19, 130.

DOI:10.1007/s11051-017-3816-8.

132

With respect to exposure durations, the retrieved studies were classified into four groups, i.e.

133 acute, subacute, subchronic or semi-chronic, and chronic. The categorisation is strongly

134 dependent on the species, e.g. maximum lifetime (Vermeire et al. 1999). Supplementary

135 Methods (Table M3) show the categories and their associated definitions that are assumed for

136 studies on rats, mice and hamsters. Acute studies, i.e. with a repeated exposure of less than 7

137 consecutive days, were disregarded in the current study as the overall aim is to investigate

138 chronic toxicity.

139 Only studies with a comprehensive report of the toxicity responses were included.

140 Biodistribution and dosimetry-based studies were not considered when they did not investigate

141 possible incidence of adverse toxic effects. Studies, in which only morphological effects of

142 exposure to micro-sized or nano-sized particles were observed (e.g. weight), were disregarded. In

143 addition, genotoxicity tests were excluded because of the difficult comparability with other

144 toxicological studies and their linkage to potential mutagenicity carcinogenic effects, which are

145 considered outside the scope of the study (Koedrith et al. 2014). Only studies including

146 investigations of non-cancer effects were considered (although studies investigating cancer

147 effects are also reported in Tables S1 and S2). Furthermore, all tests performed on animal models

148 of human susceptibility, e.g. pregnant mice (Gao et al. 2011; Warheit et al., 2015) were

149 excluded. Finally, all tests with responses and/or doses and/or particle characterisation that could

150 not be quantified properly were excluded.

151

\section{2.3. Particles properties available for statistical analysis}


Laurent A., Harkema J., Andersen E. W., Owsianiak M., Vea E. B., Jolliet O., 2017. Human health no-effect levels of $\mathrm{TiO}_{2}$ nanoparticles as a function of their primary size. Journal of Nanoparticle Research 19, 130.

DOI:10.1007/s11051-017-3816-8.

153 Over the past decade, the field of nanotoxicology has identified a relatively large number of

154 physicochemical properties of the nanoparticles that are accountable for their toxic effects. From

155 the literature, about 10 generic physicochemical properties are frequently reported as influential

156 to the fate and health effects of the nanoparticles, i.e. the primary particle size (incl. size

157 distribution), the shape (aspect ratio), the specific surface area, the surface chemistry/reactivity,

158 the composition (incl. impurities), the coating composition (if any), the crystal structure, the

159 charge, the solubility, the state of agglomeration (Zeta potential) and aggregation (Landsiedel et

160 al. 2010; Maynard and Aitken 2007; MINChar 2008; Oberdörster 2010; Stone et al. 2010a, b).

161 A case-by-case approach is advised when addressing the behaviour of nanoparticles in the

162 environment and their impacts on human health (and ecosystems) -see e.g. Stone et al. (2010a)

163 and SCENIHR (2009). Therefore, not all properties will play a same role whether carbon

164 nanotubes or nano- $\mathrm{TiO}_{2}$ are studied, for example. One of the major problems to analyse the

165 influence of these properties is the lack of comprehensive documentation in the experimental

166 studies, which render difficult the find of patterns (Clark et al. 2012). Although it is not directly

167 addressed in this study, another issue consists in the contrast between the properties of pristine

168 nanoparticles, which are manufactured nanomaterials and are the focus of most toxicological

169 studies, and those of the nanoparticles eventually embedded in consumer products and

170 potentially released to the environment in their use or disposals (Nowack et al. 2012). Properties

171 of the latter categories of particles (and their changeability after releases) are more relevant to

172 human health impact and risk assessments.(Nowack et al. 2012)

173 With respect to $\mathrm{TiO}_{2}$ nanoparticles, a number of studies have highlighted the influence on

174 the toxicity responses of several physicochemical properties, including the primary particle size

175 (Oberdörster et al. 2005), the surface treatment, e.g. presence and type of coatings (e.g. Warheit 
Laurent A., Harkema J., Andersen E. W., Owsianiak M., Vea E. B., Jolliet O., 2017. Human health no-effect levels of $\mathrm{TiO}_{2}$ nanoparticles as a function of their primary size. Journal of Nanoparticle Research 19, 130.

DOI:10.1007/s11051-017-3816-8.

176 et al. 2005), and the crystal form (e.g. Jiang et al. 2008). To comprehensively analyse their

177 influences and dependencies, a sufficiently detailed documentation of these properties is required

178 for the majority of the retained studies. Unfortunately, because of the paucity of data across the

179 retained studies, the surface-related characteristics, e.g. coatings of pigmentary particles, could

180 not be integrated. Therefore, only the primary particle size and the crystal form were analysed in

181 relation to the toxic responses, an assumption that affects the numeric estimates. Further works

182 should address those gaps.

183 For primary particle size, the values reported by the authors of the studies were considered as

184 such, although some discrepancies might occur in their characterisation across studies. It is

185 noteworthy that in most studies, data about size distribution was missing or largely insufficient to

186 allow for a comprehensive accounting of this aspect. When available, such information could

187 however be useful to investigate the influence of the particle aggregation state on the potential

188 toxicity of nanoparticles, and should thus be encompassed in future studies comparable to the

189 current one.

$190 \quad$ 2.4. Expression of animal doses

$191 \quad$ For all included experiments, each tested dose and its associated responses were individually

192 treated. A similar method as the one developed by Gold et al. (1984) (CPDB website at

193 http://potency.berkeley.edu/methods.html) was applied. All reported doses were translated into

194 average daily chronic dose rates expressed in a mass unit of the particle intake per day (d) and kg

195 body weight (kg-bw) for ingestion and inhalation exposure -see Equations 1 and 2, respectively:

$196 \quad I D_{a, \text { chronic }}=\frac{I D_{a, i} \times C F_{\text {exp }}}{B W_{a} \times C F_{i}} \quad($ Equation 1) 
Laurent A., Harkema J., Andersen E. W., Owsianiak M., Vea E. B., Jolliet O., 2017. Human health no-effect levels of $\mathrm{TiO}_{2}$ nanoparticles as a function of their primary size. Journal of Nanoparticle Research 19, 130.

DOI:10.1007/s11051-017-3816-8.

$197 I D_{a, \text { chronic }}=\frac{C_{a, i} \times I R_{a} \times C F_{\text {exp }}}{B W_{a} \times C F_{i}} \quad$ (Equation 2)

198 where $I D_{a, \text { chronic }}$ is the average daily chronic intake dose (e.g. $\mathrm{mg} / \mathrm{kg}$-bw/day) for a given animal

$199 a ; I D_{a, i}$ is the daily ingested dose (e.g. mg/day) used in the test with animal $a$ and exposure

200 duration $i ; C F_{\text {exp }}$ is the correction factor for exposure time to translate the discontinuous regimen

201 in animal test into an assumed continuous daily exposure used as target exposure (e.g. $C F_{\text {exp }}=$

$202 \mathrm{D} / 7 \times \mathrm{H} / 24$, with $\mathrm{D}=$ days of weekly exposure and $\mathrm{H}=$ hours of daily exposure); $B W_{a}$ is the

203 body weight (kg-bw) of animal $a$ (reported in studies or default values taken from US-EPA

204 (1988); $C F_{i}$ is the dimensionless correction factor for duration of the exposure $i$ (subacute,

205 subchronic, chronic; see below); $C_{a, i}$ is the concentrations $\left(\mathrm{mg} / \mathrm{m}^{3}\right)$ used in the test with animal

$206 a$ and exposure duration $i$; IR $R_{a}$ is the inhalation rate of test animal $a$ in $\mathrm{m}^{3} / \mathrm{d}$ (reported in US-

207 EPA 1988).

208 The correcting factors $C F_{i}$ from Vermeire et al. $(1999,2001)$ were used to adjust the 209 duration of the exposure, with values for subacute-to-chronic factor of 5 and subchronic-to-

210 chronic ratio of 2. They are derived for oral NOAEL data but Vermeire et al. (2001) report their

211 assumed applicability to systemic effects caused by inhalation or dermal exposures. These

212 extrapolation factors were derived from investigating chemicals effects. In the absence of any

213 data with regard to particles, it is assumed valid for the purpose of this study. Further work is

214 needed to verify and/or refine that assumption.

215 It is noteworthy that the approach to express doses as intake doses for both exposure routes

216 differs from that used in some other studies (e.g. Brown et al. 2005; Kuempel et al. 2006; 
Laurent A., Harkema J., Andersen E. W., Owsianiak M., Vea E. B., Jolliet O., 2017. Human health no-effect levels of $\mathrm{TiO}_{2}$ nanoparticles as a function of their primary size. Journal of Nanoparticle Research 19, 130.

DOI:10.1007/s11051-017-3816-8.

217 Pauluhn 2011; Oller and Oberdörster 2010). In these, the dose expression also encompasses

218 some elements of absorption by the receiving body. For example, in particle inhalation studies,

219 Jarabek et al. (2005), Kuempel et al. (2006) and Oller and Oberdörster (2010) include the

220 deposited fractions of particles in the lungs, which also depend on the agglomeration/aggregation

221 state and can be calculated via e.g. a multiple-path particle dosimetry model (e.g. Asgharian et al.

222 1995, 2001; Asgharian and Price 2007). In the current study, we intend to bring results from all

223 exposure pathways on an equal basis. In practice, this can be done before or after absorption

224 processes (e.g. after absorption from GI tract for ingestion route or from the depositions in the

225 lungs). However, the absorption mechanisms are dependent on several parameters, including

226 characteristics specific to both the particle type and the receiving animal/human body. Based on

227 the often incomplete data available in the retrieved studies and the general lack of knowledge in

228 the mechanisms governing particle absorptions, the determination of absorption fractions was

229 disregarded for all considered exposure routes. All doses for inhalation and ingestion were

230 therefore expressed as intake doses. The possibility to harmonise all doses as uptake doses,

231 reflecting the amount of nanoparticles absorbed in the body via the lungs or the gastrointestinal

232 tract, should however be explored in further studies, as it is deemed more consistent.

\section{$234 \quad$ 2.5. Review of observed toxic responses}

235 As the toxic endpoints vary considerably across the selected studies, the observed toxic

236 responses were reviewed for each single dose tested with focus on ensuring comparability and

237 harmonisation across the studies. General selection criteria were thus defined, including: (i)

238 evaluation of the incidence of adverse effects and not their severities, hence disregarding post- 
Laurent A., Harkema J., Andersen E. W., Owsianiak M., Vea E. B., Jolliet O., 2017. Human health no-effect levels of $\mathrm{TiO}_{2}$ nanoparticles as a function of their primary size. Journal of Nanoparticle Research 19, 130.

DOI:10.1007/s11051-017-3816-8.

exposure monitoring/recovery periods, which could yield different toxicity characterisation in

240 the data set but could difficultly be harmonised across studies (e.g. studies not addressing

241 recovery vs. studies addressing it); (ii) evaluation of the toxic responses based on the stained

242 sections and micrographs of exposed organs and tissues (e.g. incidence of necrosis) and/or the

243 reported levels of serum biochemical values and haematological parameters (based on statistical

244 significance when compared to controls), and the interpretation of histopathological findings

245 reported by the authors of the studies; (iii) emphasis to identify actual adverse effects. With

246 respect to the latter, the accumulation of macrophages was thus not deemed an adverse effect

247 because it was regarded as a defence mechanism, which could be triggered by other causes than

248 the exposure to the (nano)particles. Many experiment results were analysed based on the

249 reported incidence of necrosis or apoptosis, both indicative of induced inflammation. Chronic

250 alveolar inflammation was considered an adverse effect for lung toxicity. Statistically different

251 (from controls) levels of neutrophils (PMN) or some enzymes, e.g. aspartate transaminase (AST)

252 or alanine transaminase (ALT), indicative of liver toxicity and injury, were also considered as

253 markers of adverse effects. All toxic endpoints were considered equally in this review and were

254 not differentiated in the further analysis to allow retaining a sufficiently large pool of data.

255 However, ways to account for their large diversities, and thus render the different doses (e.g.

256 NOAELs), should be explored in future studies (ECHA, 2017).

257 Each dose-specific experiment was thus flagged as either a NOAEL or a lowest-observed

258 adverse effect level (LOAEL), or was not flagged if the experiment dose was lower (higher) than

259 an already-flagged NOAEL (LOAEL) for the same experiment. Although tests within each

260 single experiment were flagged as NOAEL or LOAEL (or not flagged), the data are in fact

261 interval-censored and all flagged tests should be distinguished according to three groups, i.e. (1) 
Laurent A., Harkema J., Andersen E. W., Owsianiak M., Vea E. B., Jolliet O., 2017. Human health no-effect levels of $\mathrm{TiO}_{2}$ nanoparticles as a function of their primary size. Journal of Nanoparticle Research 19, 130.

DOI:10.1007/s11051-017-3816-8.

262 those with only an identified NOAEL (i.e. left-censored), (2) those with only an identified

263 LOAEL (i.e. right-censored) and (3) those with both identified NOAEL and LOAEL in the same

264 experiment (i.e. termed "interval-censored NOAEL/LOAEL" in the following). Therefore, the

265 level at which an adverse effect occurs lies between NOAELs and LOAELs of tests belonging to

266 group 3 (hence “interval censoring”), or lies above NOAELs of group 1 (how far above is

267 unknown, hence "right-censoring”) or below LOAELs of group 2 (how far below is unknown,

268 hence "left-censoring”). In the reporting and analysis of the results, the distinction between the

269 NOAELs of groups 1 and 3 as well as that between the LOAELs of groups 2 and 3 were made by

270 considering either the whole set of NOAEL/LOAEL data or the data set limited to interval-

271 censored NOAEL/LOAELs.

272

\section{$273 \quad$ 2.6. Regression analyses}

274

Several parametric regression analyses were performed to investigate the relationships

275 between the incidence of adverse effects and the primary size and the crystallinity of the $\mathrm{TiO}_{2}$

276 particles: (i) a preliminary analysis of variance (ANOVA), (ii) multiple linear regression

277 analyses, and (iii) a regression analysis accounting for the censored nature of the data (i.e.

278 differentiating left-censored, right-censored and interval-censored data). Statistical software from

279 the R system, version 3.2.3 (R Core Team, Vienna, AT), and statistical software Stata, v. 13

280 (StataCorp LP, College Station, TX, USA), were used to perform these analyses.

281 Based on the review of the toxic responses (see Section 2.5), ANOVA tests were carried out

282 using the whole set of NOAEL/LOAEL data, testing the influence of the primary size of the

283 particles, the exposure route, and the type of toxicity response to explain $\mathrm{TiO}_{2}$ toxicity. For these 
Laurent A., Harkema J., Andersen E. W., Owsianiak M., Vea E. B., Jolliet O., 2017. Human health no-effect levels of $\mathrm{TiO}_{2}$ nanoparticles as a function of their primary size. Journal of Nanoparticle Research 19, 130.

DOI:10.1007/s11051-017-3816-8.

284 ANOVA tests, the particles in our data set were grouped into two size groups (nano-range, i.e.

285 below $100 \mathrm{~nm}$, and micro- range, above $100 \mathrm{~nm}$ ).

286 Multiple linear regression (MLR) analyses were computed on the NOAEL and LOAEL

287 identified through the review (see Section 2.5), and encompassed the following numerical and

288 categorical variables: (i) the primary size of the particles, (ii) the crystal form (relevant to $\mathrm{TiO}_{2}$ ),

289 (iii) the exposure route, (iv) the tested animal, and (v) the type of toxicity response (NOAEL or

290 LOAEL). The analyses were separately conducted on the entire set of data as well as on the data

291 set limited to interval-censored NOAEL/LOAEL values (see Section 2.5). In these regressions,

292 the primary size of the particles was included as continuous variable. The generic model of the

293 regression analysis describes NOAEL and can be expressed for an observation i with Equation 3:

$294 \log _{10}\left(N O A E L_{i}\right)=\alpha+\beta_{\text {size }} \log _{10}\left(d_{i}\right)+\beta_{\text {species-route }} I_{\text {species-route }}+\beta_{\text {cryst-an }} X_{\text {cryst-an }}+\varepsilon_{i}$ (Equation 3)

295 with $d$ the primary particle size, $\beta_{\text {size }}$ the parameter expressing the slope for the dependence on

296 primary particle size, $\beta_{\text {species, route }}$ the parameter for given species and exposure route, conditioned

297 with the Boolean variable $I_{\text {species, route }}(0,1)$, and $\beta_{\text {cryst-an }}$ the parameter for anatase crystal form,

298 conditioned with the content of anatase $X_{\text {cryst-an }}(\%)$ and $\varepsilon_{i}$ expressing a normal distribution with

299 mean 0. When only exposure route was considered as a variable (i.e. no species differentiation;

300 see Section 3.2), the parameter $\beta_{\text {species, route }}$ in Equation 1 is substituted by $\beta_{\text {route }}$.

301 To integrate the censored nature of the data into the regression analysis, an additional

302 parametric regression analysis of the censored data was conducted (Klein 2003). Such type of

303 models is commonly used for accelerated failure time modelling, and its explorative use here

304 aims to test the relationships between the size variable and the absence or incidence of adverse 
Laurent A., Harkema J., Andersen E. W., Owsianiak M., Vea E. B., Jolliet O., 2017. Human health no-effect levels of $\mathrm{TiO}_{2}$ nanoparticles as a function of their primary size. Journal of Nanoparticle Research 19, 130.

DOI:10.1007/s11051-017-3816-8.

305 effects defined as interval-censored, left-censored or right-censored data. The model expression

306 for that censoring-based regression (CR) is the same as described in Equation 1. In addition to

307 testing the statistical significance of the variables, the tested model can also describe the point

308 where adverse effects start occurring, i.e. virtually the upper achievable NOAEL.

309 The results of all regression tests were examined and interpreted based on the statistical

310 significance of the parameters and the model as a whole (p-values $<0.05)$. In addition, multiple

311 linear regression models were also validated using leave-one-out cross-validation procedure and

312 characterised with the predictive squared correlation coefficient Q2.

313

314 2.7. Extrapolations to human-equivalent doses

315 Equivalent human intake doses, i.e. NOAELs for humans, were extrapolated from average

316 daily chronic intake doses for the selected animal for ingestion and inhalation exposure routes -

317 see Equation 4.

$318 \quad N O A E L_{\text {hum }}^{e x}=\frac{N O A E L_{a}^{e x}}{A F_{a}} \times B W_{\text {hum }}$

(Equation 4)

319 With NOAEL ${ }_{\text {hum }}^{e x}$ being the NOAEL expressed as average daily intake dose for humans (in

$320 \mathrm{mg}$ /day/person) for chronic exposure route ex; NOAEL $L_{a}^{e x}$ the NOAEL expressed as average daily

321 intake dose for animal $a$ and chronic exposure route ex; $A F_{a}$ the interspecies allometric factor

322 for animal $a$; and $B W_{\text {hum }}$ Body weight (kg) of humans (70 kg; US-EPA 1988). 
Laurent A., Harkema J., Andersen E. W., Owsianiak M., Vea E. B., Jolliet O., 2017. Human health no-effect levels of $\mathrm{TiO}_{2}$ nanoparticles as a function of their primary size. Journal of Nanoparticle Research 19, 130.

DOI:10.1007/s11051-017-3816-8.

Interspecies extrapolation from animals to humans was performed by applying allometric

325 factors (Gold et al. 1984, Jarabek et al. 2005, Rosenbaum et al. 2011, Vermeire et al. 1999, 2001,

326 Vermeire et al. 1999). As defined by Vermeire et al. (2001), the interspecies factors include (i) a

327 default distribution to account for variability in specific toxicokinetics and toxicodynamics, and

328 (ii) a default factor to account for systemic differences between species caused by differences in

329 body size and related basal metabolic rate. Vermeire et al. (2001) report a geometric mean of the

330 latter equal to 1 , thus reflecting the biological assumption that all species are equally sensitive.

331 The interspecies allometric factors $A F_{a}$ thus express the systemic differences between species

332 after exposure. Three methods are commonly used to determine these factors, whether the

333 extrapolations are based on body weight, surface area or caloric demand (Vermeire et al. 1999).

334 In the current study, the recommendations of Vermeire et al. (1999, 2001), who indicate the

335 preference of extrapolations based on calorific demands, were followed, with default values of

$336 A F_{a}$ equal to 4.1 (rats), 7.3 (mice) and 4.7 (hamster; own calculation). It is noteworthy that this

337 is in contrast to some previous studies on nano-sized and micro-sized particles (e.g. Jarabek et al.

338 2005; Kuempel et al. 2006), where the allometric factor is defined by the ratios of body weights

339 between humans and animals for systemic effects, or by the ratios of lung masses or lung surface

340 areas between humans and animals for effects in the respiratory tract.

\section{3. Results and discussion}

\section{$343 \quad$ 3.1. Review results}

344 The application of selection criteria to identify relevant in vivo studies for the review (see

345 Methodology) led to shortlisting a total of 181 collected studies in 209 scientific publications to a 
Laurent A., Harkema J., Andersen E. W., Owsianiak M., Vea E. B., Jolliet O., 2017. Human health no-effect levels of $\mathrm{TiO}_{2}$ nanoparticles as a function of their primary size. Journal of Nanoparticle Research 19, 130.

DOI:10.1007/s11051-017-3816-8.

346 number of 21 retained in vivo studies addressing subacute, subchronic and chronic exposure to

$347 \mathrm{TiO}_{2}$ particles via ingestion and inhalation routes (32 scientific publications; see Tables S1 and

348 S2 and Supplementary Methods). The retained data correspond to 60 different tests, in which 17

349 NOAELs and 26 LOAELs were identified (see Table 1). The range of particle sizes over the

350 entire data set is $4 \mathrm{~nm}-450 \mathrm{~nm}$. The review details of these tests are documented in Tables S1

351 and S2 for ingestion and inhalation exposure routes, respectively.

353 Table 1 Summary of reviewed in vivo studies with ranges of NOAEL and LOAEL for $\mathrm{TiO}_{2}$

354 particles. $^{\text {a }}$

\begin{tabular}{|c|c|c|c|c|c|c|}
\hline $\begin{array}{l}\text { Exposure } \\
\text { routes }\end{array}$ & $\begin{array}{l}\text { Number of } \\
\text { studies } \\
\text { (papers) }^{b}\end{array}$ & $\begin{array}{l}\text { Number } \\
\text { of tests }\end{array}$ & $\begin{array}{l}\text { Number of } \\
\text { left-censored } \\
\text { NOAEL data }\end{array}$ & $\begin{array}{l}\text { Number of } \\
\text { right-censored } \\
\text { LOAEL data }\end{array}$ & $\begin{array}{l}\text { Number of } \\
\text { interval-censored } \\
\text { NOAEL / LOAEL } \\
\text { data }\end{array}$ & $\begin{array}{l}\text { NOAEL } \\
\text { (LOAEL) ranges } \\
(\mathrm{mg} / \mathrm{kg}-\mathrm{bw} / \mathrm{d})\end{array}$ \\
\hline Ingestion & $6(6)$ & 15 & 3 & 5 & $1 / 1$ & $\begin{array}{l}40-24000 \\
(8-1000)\end{array}$ \\
\hline Inhalation & $15(26)$ & 45 & 7 & 14 & $6 / 6$ & $\begin{array}{l}0.0836-4.05 \\
(0.0171-10.5)\end{array}$ \\
\hline $\begin{array}{l}\text { Total } \\
\text { retrieved }\end{array}$ & $21(32)$ & 60 & 10 & 19 & $7 / 7$ & - \\
\hline
\end{tabular}

$355 \quad{ }^{\mathrm{a}}$ For differentiation across species, see details in Tables S1 and S2.

$356{ }^{\mathrm{b}}$ Studies refer to a set of experiments performed by the same research group. The results of a study are

357 sometimes disseminated in several papers, hence the higher number of papers than that of studies. Tests

358 refer to experiments conducted on a given species exposed to a specific type of particles with a specific

359 exposure level.

360

361 3.2. Relationships between toxic effects and primary particle size of $\mathrm{TiO}_{2}$

362 Unlike anticipated (see, e.g. Jiang et al., 2008), none of the statistical analyses of the

363 correlation between the toxicity of $\mathrm{TiO}_{2}$ particles and their physicochemical properties showed

364 that the crystallinity of $\mathrm{TiO}_{2}$ particles expressed a statistically-significant influence on their 
Laurent A., Harkema J., Andersen E. W., Owsianiak M., Vea E. B., Jolliet O., 2017. Human health no-effect levels of $\mathrm{TiO}_{2}$ nanoparticles as a function of their primary size. Journal of Nanoparticle Research 19, 130.

DOI:10.1007/s11051-017-3816-8.

toxicity when the primary particle size was also considered. A strong correlation was observed

366 between the crystallinity and the primary size of the particles in the retained experiments (see

367 Table S3), since small-sized particles were associated with higher proportions of anatase whereas

368 larger-sized particles were dominantly in a rutile form. The crystallinity was therefore

369 disregarded from further analysis in this study although its relationship with toxicity of the

370 particles should still be explored in future research (Jiang et al. 2008). In the following

371 subsections, the analysis was therefore centered on studying the relationships between the

372 primary size and the toxicity of the particles.

373 The overall trend illustrated in Figure 1A suggests an influence of particle size when

374 classifying the data set into 2 size groups (nano-range, i.e. below $100 \mathrm{~nm}$, and micro- range,

375 above $100 \mathrm{~nm}$ ). The two-way ANOVA analysis indeed revealed statistically significant

376 differences between the size groups, classified into absence/occurrence of adverse effects, i.e.

377 NOAEL or LOAEL (see Figure 1A; all data considered, regardless of their interval-censored

378 nature) when all routes were combined $\left(\mathrm{F}_{2,40}=2.96\right.$; $\mathrm{p}$ values of 0.039 and 0.27 for the effects of

379 size and absence/occurrence of adverse effects, respectively). When only inhalation data are

380 considered, both the size and the absence/occurrence of adverse effects become statistically

381 significant $\left(\mathrm{F}_{2,30}=14.4 ; \mathrm{p}<0.005\right.$ in both cases; see Figure $\left.1 \mathrm{~B}\right)$. This suggests that in addition to

382 the influence of the size, there might be some influence of the exposure route on nanoparticle

383 toxicity. This influence was not found to be statistically significant in this ANOVA analysis

384 probably due to low number of data points. 

of $\mathrm{TiO}_{2}$ nanoparticles as a function of their primary size. Journal of Nanoparticle Research 19, 130.
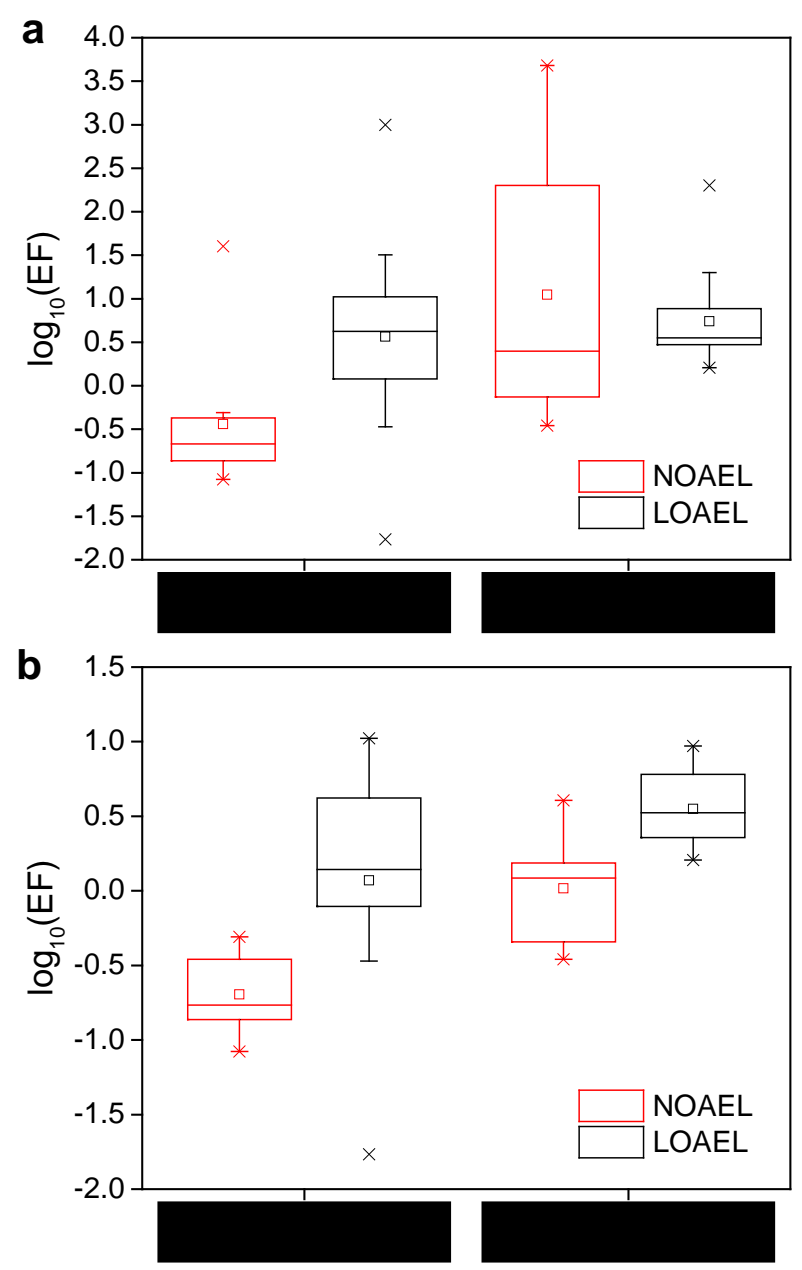

Fig. 1 Influence of the primary size on the occurrence of adverse toxic effect of $\mathrm{TiO}_{2}$ particles in nano- and micro-sized ranges for (a) the entire data set, and (b) the data set restricted to the inhalation exposure route. EFs indicated on the y-axis are either NOAEL or LOAEL data points (adjusted to average daily chronic intake doses in $\mathrm{mg} / \mathrm{kg}-\mathrm{bw} / \mathrm{d}$; see Table 1 ). Boxes indicate $25^{\text {th }}$ and $75^{\text {th }}$ percentiles, square and horizontal lines within the boxes indicate mean and median, 393 so that data points outside the fence values (in our study one data point) are considered outliers. 394 Crosses indicate $2.5^{\text {th }}$ and $95^{\text {th }}$ percentiles. 
Laurent A., Harkema J., Andersen E. W., Owsianiak M., Vea E. B., Jolliet O., 2017. Human health no-effect levels of $\mathrm{TiO}_{2}$ nanoparticles as a function of their primary size. Journal of Nanoparticle Research 19, 130.

DOI:10.1007/s11051-017-3816-8.

398 the data set limited to interval-censored NOAEL/LOAEL $(n=14)$, with and without species

399 differentiation. The considered variables are able to explain between $88 \%$ and $92 \%$ (adjusted $\mathrm{R}^{2}$ )

400 of the data variability when restricting the dataset to the most reliable data with that interval-

401 censored NOAEL/LOAEL. When considering the entire dataset, data variability increases and

402 the fraction explained is reduced to approximately $65 \%$.

403

Effect of particle size: Statistically significant associations are observed between NOAEL

404 and size-variable for the restricted interval-censored data set, with significant (i.e. below 0.05) p-

405 values of 0.004 (test with exposure route differentiation) and 0.001 (test with both species and

406 exposure route differentiation). When considering the entire dataset, the association with the

407 size-variable is significant $(\mathrm{p}=0.009)$ when only exposure route is differentiated and marginally

408 significant $(\mathrm{p}=0.049)$ when both route and species are differentiated. These results suggest a firm

409 correlation between the primary size of the particle and its toxicity. Likewise, a marked

410 differentiation between the absence or occurrence of adverse effects (i.e. NOAEL or LOAEL) is

411 overall observed (see Table 2).

413 Table 2 Results of MLR analysis for inhalation and ingestion exposure to $\mathrm{TiO}_{2}$ particles. ${ }^{\mathrm{a}}$

\begin{tabular}{|c|c|c|c|c|}
\hline Parameter & $\begin{array}{c}\text { Only interval- } \\
\text { censored } \\
\text { NOAEL/LOAEL } \\
(\mathrm{n}=14) \\
\text { Exposure route } \\
\text { differentiation } \\
\end{array}$ & $\begin{array}{c}\text { Only interval- } \\
\text { censored } \\
\text { NOAEL/LOAEL } \\
(\mathrm{n}=14) \\
\text { Species and exposure } \\
\text { route differentiation }\end{array}$ & $\begin{array}{c}\text { All NOAEL/LOAEL } \\
\text { data }(\mathrm{n}=43) \\
\text { Exposure route } \\
\text { differentiation }\end{array}$ & $\begin{array}{c}\text { All NOAEL/LOAEL } \\
\text { data }(n=43) \\
\text { Species and exposure } \\
\text { route differentiation }\end{array}$ \\
\hline Intercept & $-1.80(-2.69 ;-0.90) * *$ & $-2.31(-3.32 ; 1.29) * *$ & $-1.20(-2.00 ;-0.40) * *$ & $\begin{array}{l}-1.234(-2.02 ;-0.43) \\
* *\end{array}$ \\
\hline Log Size & $0.74(0.30 ; 1.17) * *$ & $0.87(0.471 .28) * *$ & $0.57(0.15 ; 0.99) * *$ & $0.46(0.002 ; 0.91) * *$ \\
\hline Inhalation & $\begin{array}{l}0 \text { (reference, see } \\
\text { intercept) }\end{array}$ & NA & $\begin{array}{l}0 \text { (reference, see } \\
\text { intercept) }\end{array}$ & NA \\
\hline Ingestion & $1.76(1.23 ; 2.30) * *$ & NA & $1.90(1.42 ; 2,39) * *$ & NA \\
\hline $\begin{array}{l}\text { Ingestion, } \\
\text { mouse }\end{array}$ & NA & $1.97(1.37 ; 2.57) * *$ & NA & $2.08(1.36 ; 2.80) * *$ \\
\hline
\end{tabular}


Laurent A., Harkema J., Andersen E. W., Owsianiak M., Vea E. B., Jolliet O., 2017. Human health no-effect levels of $\mathrm{TiO}_{2}$ nanoparticles as a function of their primary size. Journal of Nanoparticle Research 19, 130.

DOI: $10.1007 / \mathrm{s} 11051-017-3816-8$.

\begin{tabular}{|l|l|l|l|l|}
\hline Ingestion, rat & NA & NA & NA & $2.53(1.64 ; 3.43) * *$ \\
\hline $\begin{array}{l}\text { Inhalation, } \\
\text { mouse }\end{array}$ & NA & $0.51(0.04 ; 1.05) *$ & NA & $\begin{array}{l}\text { (reference, see } \\
\text { intercept) }\end{array}$ \\
\hline $\begin{array}{l}\text { Inhalation, } \\
\text { rat }\end{array}$ & NA & $0.141(0.36 ; 0.64)$ & NA & $0.47(-0.13 ; 1.08)$ \\
\hline $\begin{array}{l}\text { Inhalation, } \\
\text { hamster }\end{array}$ & NA & $\begin{array}{l}0 \text { (reference, see } \\
\text { intercept })\end{array}$ & NA & $0.21(-0.64 ; 1.05)$ \\
\hline LOAEL & $0.73(0.36 ; 1.09) * *$ & $0.72(0.40 ; 1.04) * *$ & $0.31(-0.12 ; 0.73)$ & $0.21(-0.25 ; 0.67)$ \\
\hline Adj. R2 & 0.884 & 0.918 & 0.648 & 0.656 \\
\hline Q2 (LOO) & 0.841 & 0.894 & 0.589 & 0.524 \\
\hline $\begin{array}{l}\text { p-value for } \\
\text { model }\end{array}$ & $1.47 \mathrm{E}-05 * *$ & $5.55 \mathrm{E}-05 * *$ & $1.41 \mathrm{E}-09 * *$ & $2.79 \mathrm{E}-08 * *$ \\
\hline
\end{tabular}

414 a Statistically-significant results, assumed with $\mathrm{p}<0.05$, are indicated by asterisks “***, results with

$4150.05<\mathrm{p}<0.1$ are indicated by “*”. 95\% confidence intervals (95\% CI) are provided in brackets. NA: not 416 applicable.

418 The best estimate of the size parameter slope $\beta_{\text {size }}$ that expresses the increase in the $419 \log _{10}(\mathrm{NOAEL})$ as a function of the $\log _{10}$ (particle size) varies between 0.46 and 0.87 (see Table 420 2). This supports the observations that toxic effects continuously decrease as the primary particle

421 size increases. These results imply that an exposure to $\mathrm{TiO}_{2}$ nanoparticles of 10 -nm primary size 422 would lead to toxic effects approximately 2.9-7.5 times higher than a same exposure to $\mathrm{TiO}_{2}$ 423 particles of 100-nm primary size (range of 1-19 when considering the positive 95\% CIs reported 424 in Table 2). This finding, especially the numerical estimates, should be considered with care 425 because physicochemical properties other than the particle size and that are not investigated in 426 the present study might significantly alter the reported trends. For example, the surface coatings 427 is known to significantly influence the toxicity of the nanoparticles, and even though our review 428 disregarded coated nanomaterials, the tested particles may still happen to be doped and/or 429 affected by the test media, as these aspects are not always monitored and reported transparently 430 in toxicological studies (Clark et al., 2012; Warheit et al., 2005; Yang et al. 2014). 
Laurent A., Harkema J., Andersen E. W., Owsianiak M., Vea E. B., Jolliet O., 2017. Human health no-effect levels of $\mathrm{TiO}_{2}$ nanoparticles as a function of their primary size. Journal of Nanoparticle Research 19, 130.

DOI:10.1007/s11051-017-3816-8.

431 This trend of a positive slope $\beta_{\text {size }}$ can also be observed when performing regression analyses

432 taking into account the censored nature of the data (i.e. Censoring-based Regression - CR

433 analysis; see Section 2.6), where positive values of the slope $\beta_{\text {size }}$ are obtained (0.80 and 0.41 for

434 species-route differentiation and only route differentiation, respectively; see Tables S4 and S5).

435 However, it should be noted that these CR tests, although deemed the most consistent when

436 taking the entire set of available data, did not reveal any statistical significance with p-values

437 above 0.05 (Tables S4 and S5). A strong dependence on the inclusion and exclusion of data in

438 this statistical test (data not shown) suggests that further attempts at the CR application should be

439 made when larger and more consistent data sets become available.

440 Exposure route: Figure 2 plots the size-differentiated NOAEL functions obtained from the

441 results of the different regression analyses. As reflected by the highly significant coefficient for

442 ingestion (versus inhalation) of close to 1.8-1.9 in both experiment only differentiating the

443 exposure route, the NOAEL values are approximately 60-80 times lower for inhalation exposure

444 than for ingestion. As also illustrated in Figure 2, the variations between the estimates of the

445 slope $\beta$ size are strongly dependent on the data set considered and whether or not only interval-

446 censored NOAEL/LOAEL data are considered (thus disregarding left- and right-censored

447 NOAEL and LOAEL data points). Accounting for the entire data set (i.e. 43 data points)

448 substantially extends the number of data, whereas the data set limited to interval-censored data

449 (i.e. 14 data points) is deemed more accurate. 

of $\mathrm{TiO}_{2}$ nanoparticles as a function of their primary size. Journal of Nanoparticle Research 19, 130.

DOI:10.1007/s11051-017-3816-8.
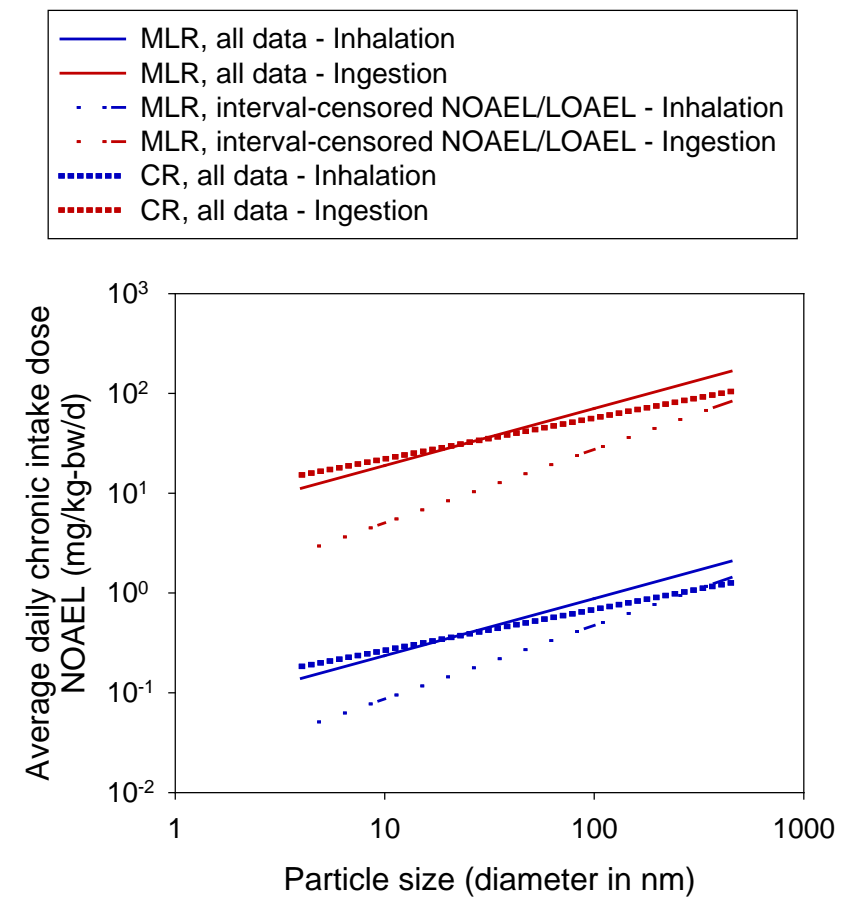

451 Fig. 2 NOAEL resulting from regression analyses for inhalation and ingestion exposure to $\mathrm{TiO}_{2}$ 452 particles (size range: 4-450 nm). Inclusion of different data sets (all data or interval-censored 453 NOAEL/LOAEL only) and regression tests (multiple linear regression, MLR, or censoring-based 454 regression, CR) differentiate the results from the regression tests, i.e. parameter values in 455 Equation 4, and hence the different curves. Interval-censored regression data accounting for the 456 censored nature of the data are only presented for indicative purposes as no statistically457 significant slope for the size were observed (see Tables S4 and S5).

Species differentiation: Differentiating the number of species in addition to the exposure

460 route only slightly increases the adjusted $\mathrm{R}^{2}$ for the restricted set limited to interval-censored 461 NOAELs/LOAELs, whereas it does not bring any increase in adjusted $\mathrm{R}^{2}$ when considering the 462 entire data set. With consideration to the restricted data set, for which there are little data for a 463 relatively large number of variables, a regression analysis made with only a differentiation 464 between exposure routes seems more appropriate. 
Laurent A., Harkema J., Andersen E. W., Owsianiak M., Vea E. B., Jolliet O., 2017. Human health no-effect levels of $\mathrm{TiO}_{2}$ nanoparticles as a function of their primary size. Journal of Nanoparticle Research 19, 130.

DOI:10.1007/s11051-017-3816-8.

Albeit their limitation to the case of $\mathrm{TiO}_{2}$ nanoparticles, our findings thus provide two major

466 advances in the assessment of the toxic effects of nanoparticles: (i) a quantitative measure of the

467 association between toxic effects and primary sizes of nanoparticles; and (ii) an expression of

468 toxic effects in a meaningful metric. Many studies have reported the different magnitudes of

469 effects on animals following exposure to different sizes of nanoparticles or to either nano-scale

470 or micro-scale particles, but none managed to quantify this difference for entire size ranges, thus

471 providing continuity and allowing for useful predictions. Furthermore, the utilization of mass-

472 based metrics alone have been demonstrated not to be valid for capturing the effects of

473 nanoparticles, and other complementary metrics based on surface area or particle numbers have

474 been proposed to account for the particle sizes (Oberdörster et al. 2005). The above findings

475 advance towards the determination of a meaningful, operational metric to express exposure

476 levels, even though it only relies on the study of the primary size and ignores potential influences

477 of other physicochemical properties of nanoparticles. The mass-based exposure levels (translated

478 into intake doses) are expressed as a function of the primary particle size, thus implicitly

479 accounting for the differences in the surface areas and particle numbers. Even for the inhalation

480 pathway, in which the absorption is strongly dependent on the state of agglomeration and

481 aggregation, aggregates of same sizes but with different primary sizes can lead to different toxic

482 responses (Ferin et al. 1992), thus indicating possible disaggregation mechanisms after intake

483 and attesting the strong influence of the primary particle size in the toxic effects. This therefore

484 supports our assertion that, given the current state of knowledge, the expression of NOAEL as a

485 function of the primary size as illustrated in Figure 2 can adequately capture the nano-scale-

486 specific toxicity of $\mathrm{TiO}_{2}$ particles while also allowing characterization of micro-sized particles,

487 and thus address the metrics issue raised in earlier studies. Further research is however needed to 
Laurent A., Harkema J., Andersen E. W., Owsianiak M., Vea E. B., Jolliet O., 2017. Human health no-effect levels of $\mathrm{TiO}_{2}$ nanoparticles as a function of their primary size. Journal of Nanoparticle Research 19, 130.

DOI:10.1007/s11051-017-3816-8.

explore how the inclusion of more physicochemical properties can refine this expression of the

489 NOAEL and to what extent this finding applies to other nanoparticles.

\section{3.3. Implications for assessing human health risks and impacts}

\section{3.3.1. Derivation of human NOAEL}

493 A direct consequence of the aforementioned findings is the opportunity to determine

494 NOAEL values for humans as function of the primary particle sizes. Based on the regression 495 analyses in Section 3.2.2, the statistical results from the data set limited to the interval-censored 496 NOAEL/LOAEL data that only distinguish between exposure routes without species

497 differentiation were retained as basis for deriving the human NOAEL. These results presented 498 high statistical significance for the different variable estimates. As reflected in Figure S1, they 499 also show conservative estimates once the animal data were converted into human-equivalent500 exposure levels, compared to the use of the entire data set. Within the data-defined size range (4$501450 \mathrm{~nm}$ ), Equations 5 and 6 express these relationships for $\mathrm{TiO}_{2}$ for both inhalation and ingestion 502 routes, respectively (with $d$ the primary size of the particles in $\mathrm{nm}$; and NOAEL hum in $503 \mathrm{mg} /$ person/day).

$504 \quad N O A E L_{\text {hum }}^{\text {inh }}=70\left[10^{(-2.620+0.796 \times \log (d))}\right]=1.680 \times 10^{-1} \times d^{0.796} \quad$ (Equation 5)

$505 \quad$ NOAEL $L_{\text {hum }}^{\text {ing }}=70\left[10^{(-1.028+0.796 \times \log (d))}\right]=6.567 \times d^{0.796} \quad$ (Equation 6)

507 It should be noted that the conversion to human exposure levels was performed on the 508 original data. Therefore the run of new regression analyses was required to obtain the parameter 
Laurent A., Harkema J., Andersen E. W., Owsianiak M., Vea E. B., Jolliet O., 2017. Human health no-effect levels of $\mathrm{TiO}_{2}$ nanoparticles as a function of their primary size. Journal of Nanoparticle Research 19, 130.

DOI:10.1007/s11051-017-3816-8.

509 estimates although the results are very similar to those reported in Table 2 (i.e. statistical

510 significance observed for all parameters and slope changed from 0.74 to 0.80 ; see Table S6).

511 Because of the large uncertainties inherent to the determination of Equation 5 and 6 (see Section

5122 and regression result analysis in Section 3.2.2), the above equations are not intended to model

513 and predict human NOAELs as a default method. However, they are believed to present a useful

514 and complementary approach to existing approaches encompassing reviews and selections of

515 specific toxicological test results (e.g. Christensen et al. 2011), and are deemed relevant for 516 screening purposes in the evaluation of risks and impacts of $\mathrm{TiO}_{2}$ nanoparticles (see following

517 Section 3.3.2).

518

519 3.3.2. Possible use in RA

520 A major concern about health effects of nanoparticles stems from potential occupational and

521 consumer exposure (via inhalation and ingestion). As illustrated in Figure 3, the findings of this

522 study show a relatively good agreement with the exposure limits recommended by the National

523 Institute of Occupational Safety and Health (NIOSH) once these are translated into intake doses

524 (Supplementary Methods and NIOSH 2011). For inhalation of $\mathrm{TiO}_{2}$ (blue curves), the

525 discontinuous exposure NIOSH thresholds and ranges, which differentiate the nano-scale and the

526 micro-scale domains based on particle archetypes (NIOSH 2011), closely follow the proposed

527 continuous size-dependent NOAELs. When considering the data ranges of the present study (i.e.

528 4-450 $\mathrm{nm}$ ), the current study tends to yield more conservative estimates in the lower nano-sized

529 and micro-sized ranges for inhalation. Overall, these comparisons therefore suggest that the

530 findings are consistent with existing recommendations (e.g. NIOSH 2011) and epidemiological

531 observations (e.g. Boffetta et al. 2004), although adjustments in recommended exposure 
Laurent A., Harkema J., Andersen E. W., Owsianiak M., Vea E. B., Jolliet O., 2017. Human health no-effect levels of $\mathrm{TiO}_{2}$ nanoparticles as a function of their primary size. Journal of Nanoparticle Research 19, 130.

DOI:10.1007/s11051-017-3816-8.

532 thresholds should be envisaged to integrate a continuous size dependency and more conservative

533 estimations.

534 With regard to ingestion exposure, some concerns have emerged with the ingestion of $\mathrm{TiO}_{2}$ as

535 food additive (i.e. E171; primarily micro-sized). Although it could not establish an acceptable

536 daily intake, the European Food Safety Authority (EFSA) Scientific Panel on Food Additives

537 and Nutrient Sources recently highlighted a NOAEL of $2250 \mathrm{mg} \mathrm{TiO} / / \mathrm{kg}$-bw/d obtained for rats

538 exposed in a chronic study (103 weeks) to ingestion of E171 (EFSA, 2016; NCI, 1979). When

539 translated into human-equivalent intake doses (see Section 2.7), this resulted in a human NOAEL

540 1-2 orders of magnitude higher than our results for the same size range -see Figure 3. While

541 indicating the conservative nature of this NOAEL, this difference may be explained by the

542 different properties of the food additive $\mathrm{E} 171$ and the $\mathrm{TiO}_{2}$ nanoparticles tested in the other

543 ingestion exposure studies supporting our results (e.g. rutile form, etc.; see Table S1; see also

544 Yang et al., 2014). It is also noteworthy that in actual exposure situations, an important

545 proportion of the particles would remain sorbed to the food matrix during the digestion process

546 and may thus not be available for absorption through the gastrointestinal tract. In contrast,

547 nanoparticles used in toxicological studies are typically not bound to any matrix, which may

548 result in a higher absorption rate. Further investigation is therefore required to evaluate the actual

549 toxic effects of nanoparticles present in consumer products (Nowack et al. 2012; EFSA, 2016;

550 Yang et al., 2014). 


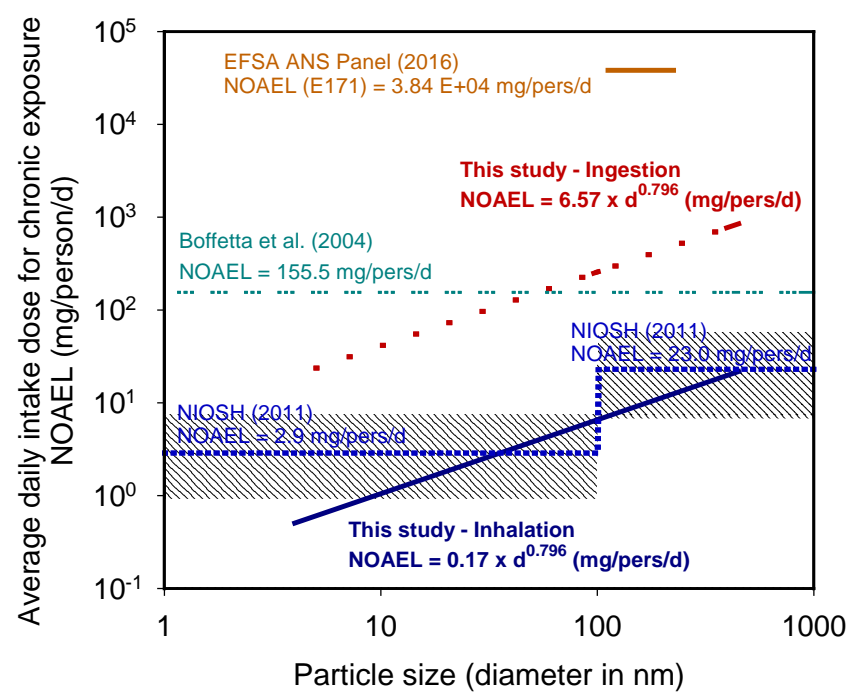

553 Fig. 3 Comparisons of NOAEL for humans for chronic inhalation and ingestion exposure to 554 nano-sized and micro-sized $\mathrm{TiO}_{2}$ particles (NOAEL expressed as average daily intake doses in $555 \mathrm{mg} /$ person/day), and assuming that coatings on pigmentary particles do not lead to artefacts (see

556 Section 2.3). The slope value for $\mathrm{TiO}_{2}$ particles is 0.796 (95\% CI: 0.43-1.16). External data were 557 used to compare with the results from the current study (ingestion: NOAEL value for E171 558 highlighted by EFSA ANS Panel (2016); inhalation: epidemiological study by Bofetta et al. 559 (2004); inhalation: recommended thresholds by NIOSH (2011)). The hatched area illustrates the 560 range of inhalation exposure levels corresponding to NOAELs for noncarcinogenic effects as 561 identified by NIOSH (2011); the blue-dotted line indicates the recommended NIOSH thresholds 562 relating to cancer effects and regarded as default (NIOSH 2011). Background details pertaining 563 to these graphs are documented in Table S6 and in Supplementary Methods.

The dependence of the NOAEL on the primary size of the particles, including 95\% 566 confidence intervals, allows making refined, case-specific human health risk assessments, 567 bringing more consistency to earlier attempts (Christensen et al. 2011; Kuempel et al. 2012; Som 568 et al. 2013). Exposure situations, which are typically defined for a specific type of nanoparticles, 569 can thus be compared to the human NOAEL obtained across a range of primary sizes. Table 3 570 illustrates the application of the approach to occupational exposures to $\mathrm{TiO}_{2}$ nanoparticles. 
Laurent A., Harkema J., Andersen E. W., Owsianiak M., Vea E. B., Jolliet O., 2017. Human health no-effect levels of $\mathrm{TiO}_{2}$ nanoparticles as a function of their primary size. Journal of Nanoparticle Research 19, 130.

DOI:10.1007/s11051-017-3816-8.

571 Derived margins of exposure are observed to be well below potential uncertainty factors of 100

572 or 1000 for occupational studies. It suggests that present $\mathrm{TiO}_{2}$ exposure may be high for workers,

573 although occupational risks may be mitigated by the use of respiratory protection (see Table 3).

575 Table 3 Illustrative application of the developed NOAEL approach for human health risk

576 assessment of $\mathrm{TiO}_{2}$ occupational exposure situations. ${ }^{\mathrm{a}}$

\begin{tabular}{|l|l|l|l|}
\hline Exposure situations & $\begin{array}{l}\text { Average daily intake } \\
\text { (mg/person/day) }\end{array}$ & $\begin{array}{l}\text { NOAEL } \\
\text { (mg/person/day) }\end{array}$ & Margin of Exposure \\
\hline $\begin{array}{l}\text { Collection of } \mathrm{TiO}_{2} \text { (manufacturing) } \\
\text { - without respiratory protection }\end{array}$ & $6.3 \mathrm{E}-2$ & $\begin{array}{l}1.2 \\
(0.5-3.0)\end{array}$ & $\begin{array}{l}19.3 \\
(7.8-47.5)\end{array}$ \\
\hline $\begin{array}{l}\text { Collection of } \mathrm{TiO}_{2} \text { (manufacturing) } \\
\text { - with respiratory protection }\end{array}$ & $3.4 \mathrm{E}-6$ & $\begin{array}{l}1.2 \\
(0.5-3.0)\end{array}$ & $\begin{array}{l}3.6 \mathrm{E}+5 \\
(1.4 \mathrm{E}+5-8.8 \mathrm{E}+5)\end{array}$ \\
\hline Bagging of $\mathrm{TiO}_{2}$ (manufacturing) & $3.2 \mathrm{E}-1$ & $\begin{array}{l}2.5 \\
(0.7-8.7)\end{array}$ & $\begin{array}{l}7.9 \\
(2.3-27.0)\end{array}$ \\
\hline
\end{tabular}

a Background details pertaining to these results are documented in Supplementary Methods; 95\% confidence intervals are given in brackets for NOAEL and resulting margins of exposure. Data for occupational exposure data extracted from Koivisto et al. (2012a, b). Primary sizes of 12 and $30 \mathrm{~nm}$ were considered for collection and bagging of $\mathrm{TiO}_{2}$, respectively (see details in Supplementary Methods and

581 Equations 5 and 6).

\subsubsection{Possible use in LCIA}

In line with common practice in life cycle impact assessment (e.g. Rosenbaum et al. 2011),

585 Equations 5 and 6 can also be used to calculate effective doses ED50, i.e. chronic doses causing 586 an adverse effect probability of $50 \%$, to allow the calculation of characterization factors for $\mathrm{TiO}_{2}$

587 particles, see for example Ettrup et al. (2016).

\section{Conclusions and outlook}


Laurent A., Harkema J., Andersen E. W., Owsianiak M., Vea E. B., Jolliet O., 2017. Human health no-effect levels of $\mathrm{TiO}_{2}$ nanoparticles as a function of their primary size. Journal of Nanoparticle Research 19, 130.

DOI:10.1007/s11051-017-3816-8.

590 By demonstrating that it is feasible to integrate physicochemical properties into the

591 definition of NOAEL, our proposed approach and its application to $\mathrm{TiO}_{2}$ nanoparticles, albeit

592 limited due to the difficulties surrounding coatings, can provide support for risk assessment of

593 nanomaterials and life cycle assessment of nanoproducts. Until more comprehensive

594 occupational human exposure and response data become available, our work can aid check

595 and/or develop risk and life cycle assessment guidelines to ensure low risk exposures for

596 consumers and workers. We therefore regard this study as a first step towards making use of the

597 already large and increasing body of toxicological studies on nanoparticles and thus enable more

598 consistent risk assessments and life cycle assessments.

599 However, our study clearly reflected that more data are required to (i) refine the assumptions

600 performed for translating and harmonizing the tested doses across different experimental settings

601 (e.g. harmonizing the diversity of toxic endpoints) and for deriving chronic NOAELs for humans

602 (see Sections 2.1-2.7 and Supplementary Methods); (ii) match the tested particles with those that

603 are present in consumer products or subject to worker exposure; and (iii) integrate in the

604 proposed methodology more toxicological data and encompass more physicochemical properties.

605 Increasing consistency in reporting practice for toxicological studies, as recommended by Clark

606 et al. (2012), should allow for studying a larger set of relevant particle properties, e.g. surface

607 properties like coatings. The present approach should also be applied to other relevant types of

608 nanoparticles, like silica, silver or carbon-based nanoparticles, ultimately contributing to holistic

609 appraisals of the risks and impacts of nanotechnologies.

610

\section{5. Electronic Supplementary Materials}


Laurent A., Harkema J., Andersen E. W., Owsianiak M., Vea E. B., Jolliet O., 2017. Human health no-effect levels of $\mathrm{TiO}_{2}$ nanoparticles as a function of their primary size. Journal of Nanoparticle Research 19, 130.

DOI:10.1007/s11051-017-3816-8.

612 Electronic Supplementary Materials, including Supplementary Tables, Supplementary

613 Figure and Supplementary Methods, accompanies this paper. The Supplementary Tables report

614 the detailed results from the application of the methodology to micro- and nano-sized $\mathrm{TiO}_{2}$

615 particles. The Supplementary Methods contain an account of the methodology for analyzing the

616 relationships between nanoparticle toxicity and their physicochemical properties, as

617 complementary to the Methods section. The Supplementary Methods also document the

618 background data for the examples illustrating potential applications of the results to risk

619 assessment studies.

620

621 6. Acknowledgements

622 The authors wish to thank Tobias Walser, Stefanie Hellweg, Michael Z. Hauschild, Peter

623 Fantke and Brenda Gillespie for fruitful insights in the course of the work. A.L. gratefully

624 acknowledges the financial support provided by Augustinus Fonden, Oticon Fonden and the 3R

625 Research School of the Technical University of Denmark.

626

627

7. Declaration of interest

628 The authors declare no competing financial interests.

\section{References}

631 Aitken RJ, Hankin SM, Ross B, Tran CL, Stone V, Fernandes TF, Donaldson K, Duffin R, 632 Chaudhry Q, Wilkins TA, Wilkins SA, Levy LS, Rocks SA, Maynard A (2009) 
Laurent A., Harkema J., Andersen E. W., Owsianiak M., Vea E. B., Jolliet O., 2017. Human health no-effect levels of $\mathrm{TiO}_{2}$ nanoparticles as a function of their primary size. Journal of Nanoparticle Research 19, 130. DOI:10.1007/s11051-017-3816-8.

633

634

635

636

637

638

639

640

641

642

643

644

645

646

647

648

649

650

651

652

653

654

655

656

657

658

659

EMERGNANO: A review of completed and near completed environment, health and safety research on nanomaterials and nanotechnology. Report TM/09/01. IOM, Edinburgh, UK.

Aschberger K, Micheletti C, Sokull-Klüttgen B, Christensen FM (2011) Analysis of currently available data for characterising the risk of engineered nanomaterials to the environment and human health — Lessons learned from four case studies. Environ Int 37:1143-1156.

Asgharian B, Wood R, Schlesinger RB (1995) Empirical modeling of particle deposition in the alveolar region of the lungs: A basis for interspecies extrapolation. Fund Appl Toxicol 27:232-238

Asgharian B, Hofmann W, Bergmann R (2001) Particle deposition in a multiple-path model of the human lung. Aerosol Sci Technol 34:332-339

Asgharian B, Price OT (2007) Deposition of ultrafine (NANO) particles in the human lung. Inhal Toxicol 19:1045-1054.

Bakand S, Hayes A, Dechsakulthorn F (2012) Nanoparticles: A review of particle toxicology following inhalation exposure. Inhal Toxicol 24:125-135.

Boffetta P, Soutar A, Cherrie JW, Granath F, Andersen A, Anttila A et al. (2004) Mortality among workers employed in the titanium dioxide production industry in Europe. Cancer Causes Control 15:697-706.

Brown J, Wilson W, Grant L (2005) Dosimetric comparisons of particle deposition and retention in rats and humans. Inhal Toxicol 17:355-385.

Christensen FM, Johnston HJ, Stone V, Aitken RJ, Hankin S, Peters S, Aschberger K (2011) Nano- $\mathrm{TiO}_{2}$-feasibility and challenges for human health risk assessment based on open literature. Nanotoxicology 5:110-124.

Clark K, van Tongeren M, Christensen FM, Brouwer D, Nowack B, Gottschalk F et al. (2012) Limitations and information needs for engineered nanomaterial-specific exposure estimation and scenarios: recommendations for improved reporting practices. J Nanopart Res 14:1-14.

Driscoll KE, Lindenschmidt RC, Maurer JK, Perkins L, Perkins M, Higgins J (1991) Pulmonary response to inhaled silica or titanium dioxide. Toxicol Appl Pharmacol 111:201-210. 
Laurent A., Harkema J., Andersen E. W., Owsianiak M., Vea E. B., Jolliet O., 2017. Human health no-effect levels of $\mathrm{TiO}_{2}$ nanoparticles as a function of their primary size. Journal of Nanoparticle Research 19, 130. DOI:10.1007/s11051-017-3816-8.

660 Driscoll KE, Costa DL, Hatch G, Henderson R, Oberdorster G, Salem H, Schlesinger RB (2000)

661 Intratracheal Instillation as an Exposure Technique for the Evaluation of Respiratory Tract

662 Toxicity: Uses and Limitations. Toxicol. Sci. 55, 24-35.

663 ECHA (2017) Guidance on information requirements and chemical safety assessment. Appendix

R.6-1: Recommendations for nanomaterials applicable to the Guidance on QSARs and

Grouping of Chemicals. Draft version. V. 1.0. European Chemicals Agency, Helsinki, FI.

EFSA ANS Panel (EFSA Panel on Food Additives and Nutrient Sources added to Food), 2016.

Scientific Opinion on the re-evaluation of titanium dioxide (E 171) as a food additive. EFSA Journal 14:4545, 83 pp. doi:10.2903/j.efsa.2016.4545.

Ettrup K, Kounina A, Hansen SF, Meesters JAJ, Vea EB, Laurent A (2017) Development of comparative toxicity potentials of $\mathrm{TiO}_{2}$ nanoparticles for use in life cycle assessment.

672 Ferin J, Oberdörster G, Penney D (1992) Pulmonary retention of ultrafine and fine particles in 673 rats. Am J Respir Cell Mol Biol 6:535-542.

674 Gao Y, Gopee NV, Howard PC, Yu L (2011) Proteomic analysis of early response lymph node proteins in mice treated with titanium dioxide nanoparticles. J Proteomics 74:2745-2759.

676 Gold LS, Sawyer CB, Magaw R, Backman GM, de Veciana M, Levinson R, Hooper NK, 677 Havender WR, Bernstein L, Peto R, Pike MC, Ames BN (1984) A carcinogenic potency 678 database of the standardized results of animal bioassays. Environ Health Perspect 58:9-319.

679 Grieger KD, Laurent A, Miseljic M, Christensen F, Baun A, Olsen SI (2012) Analysis of current 680 research addressing complementary use of life-cycle assessment and risk assessment for

683 Hendren CO, Mesnard X, Dröge J, Wiesner MR (2011) Estimating Production Data for Five 684 Engineered Nanomaterials As a Basis for Exposure Assessment. Environ Sci Technol $685 \quad 45: 2562-2569$.

686 Jarabek A, Asgharian B, Miller F (2005) Dosimetric adjustments for interspecies extrapolation of 687 inhaled poorly soluble particles (PSP). Inhal Toxicol 17:317-334. 
Laurent A., Harkema J., Andersen E. W., Owsianiak M., Vea E. B., Jolliet O., 2017. Human health no-effect levels of $\mathrm{TiO}_{2}$ nanoparticles as a function of their primary size. Journal of Nanoparticle Research 19, 130. DOI:10.1007/s11051-017-3816-8.

688

689

690

691

692

693

694

695

696

697

698

699

700

701

702

703

704

705

706

707

708

709

710

711

712

713

714

715

716

Jiang J, Oberdörster G, Elder A, Gelein R, Mercer P, Biswas P (2008) Does nanoparticle activity depend upon size and crystal phase? Nanotoxicology 2, 33-42.

Jolliet O, Rosenbaum RK, Laurent A (2014) Life Cycle Risks and Impacts of Nanotechnologies. In: Nanotechnology and Human Health; Malsch I and Emond C, Eds.; ISBN 9780849381447. 276 pp. Taylor \& Francis: Boca Raton, FL, USA.

Keller AA, McFerran S, Lazareva A, Suh S (2013) Global life cycle releases of engineered nanomaterials. J Nanopart Res 15:1692.

Klein JP, Moeschberger ML (2003) Survival Analysis: Techniques for Censored and Truncated Data. Springer: New York, NY, USA.

Koedrith P, Boonprasert R, Kwon JY, Kim I-S, Seo YR (2014) Recent toxicological investigations of metal or metal oxide nanoparticles in mammalian models in vitro and in vivo: DNA damaging potential, and relevant physicochemical characteristics. Mol Cell Toxicol 10:107-126.

Koivisto AJ, Lyyränen J, Auvinen A, Vanhala E, Hämeri K, Tuomi T et al. (2012a) Industrial worker exposure to airborne particles during the packing of pigment and nanoscale titanium dioxide. Inhal Toxicol 24:839-849.

Koivisto AJ, Aromaa M, Mäkelä JM, Pasanen P, Hussein T, Hämeri K (2012b) Concept to estimate regional inhalation dose of industrially synthesized nanoparticles. ACS Nano 6:1195-1203.

Krug H (2014) Nanosafety Research—Are We on the Right Track? Angew. Chem. Int. Ed. 53, 12304-12319.

Kuempel ED, Tran CL, Castranova V, Bailer AJ (2006) Lung dosimetry and risk assessment of nanoparticles: Evaluating and extending current models in rats and humans. Inhal Toxicol 18:717-724.

Kuempel ED, Geraci CL, Schulte PA (2012) Risk assessment and risk management of nanomaterials in the workplace: Translating research to practice. Ann Occup Hyg 56:491505.

Landsiedel R, Ma-Hock L, Kroll A, Hahn D, Schnekenburger J, Wiench K, Wohlleben W (2010) Testing metal-oxide nanomaterials for human safety. Adv Mater 22:2601-2627. 
Laurent A., Harkema J., Andersen E. W., Owsianiak M., Vea E. B., Jolliet O., 2017. Human health no-effect levels of $\mathrm{TiO}_{2}$ nanoparticles as a function of their primary size. Journal of Nanoparticle Research 19, 130. DOI:10.1007/s11051-017-3816-8.

717 Maynard AD, Aitken RJ, Butz T, Colvin V, Donaldson K, Oberdörster G, et al. (2006) Safe 718 handling of nanotechnology. Nature 444:267-269.

719 Maynard AD, Aitken RJ (2007) Assessing exposure to airborne nanomaterials: Current abilities 720 and future requirements. Nanotoxicology 1:26-41.

721 MINChar (2008) Physicochemical Parameters List: Recommended Minimum Physical and 722 Chemical Parameters for Characterizing Nanomaterials on Toxicology Studies. Woodrow 723 Wilson International Center for Scholars: Washington, DC, USA.

724 Mitrano DM, Motellier S, Clavaguera S, Nowack B (2015) Review of nanomaterial aging and 725 transformations through the life cycle of nano-enhanced products. Environ Int 77:132-147.

726 NCI (National Cancer Institute) (1979) Bioassay of Titanium Dioxide for Possible

727 Carcinogenicity. Technical Report Series No 97. NCI, Rockville, MD, US.

728 Nel A, Xia T, Mädler L, Li N (2006) Toxic potential of materials at the nanolevel. Science 729 311:622-627.

730 NIOSH (2011) Occupational Exposure to Titanium Dioxide; Current Intelligence Bulletin 63;

731 DHHS (NIOSH) Publication No. 2011-160; 140 pp. Department of Health and Human Services, Centers for Disease Control and Prevention, National Institute for Occupational Safety and Health: Atlanta, GA, USA.

Nowack B, Ranville JF, Diamond S, Gallego-Urrea J, Metcalfe C, Rose J, Horne N, Koelmans AA, Klaine SJ (2012) Potential scenarios for nanomaterial release and subsequent alteration in the environment. Environ Toxicol Chem 31:50-59.

Oberdörster G (2010) Safety assessment for nanotechnology and nanomedicine: Concepts of nanotoxicology. J Intern Med 267:89-105.

739 Oberdörster G, Oberdörster E, Oberdöster J (2005) Nanotoxicology: An emerging discipline evolving from studies of ultrafine particles. Environ Health Perspect 113:823-839.

741 Oller AR, Oberdörster G (2010) Incorporation of particle size differences between animal studies 742 and human workplace aerosols for deriving exposure limit values. Regul Toxicol Pharmacol $743 \quad 57: 181-194$.

744 Pauluhn J (2011) Poorly soluble particulates: Searching for a unifying denominator of 745 nanoparticles and fine particles for DNEL estimation. Toxicology 279:176-188. 
Laurent A., Harkema J., Andersen E. W., Owsianiak M., Vea E. B., Jolliet O., 2017. Human health no-effect levels of $\mathrm{TiO}_{2}$ nanoparticles as a function of their primary size. Journal of Nanoparticle Research 19, 130. DOI:10.1007/s11051-017-3816-8.

746 Rosenbaum RK, Huijbregts MAJ, Henderson AD, Margni M, McKone TE, van de Meent D, Hauschild MZ, Shaked S, Li DS, Gold LS, Jolliet O (2011) USEtox human exposure and

Savolainen K, Alenius H, Norppa H, Pylkkänen L, Tuomi T, Kasper G (2010) Risk assessment toxicity factors for comparative assessment of toxic emissions in life cycle analysis:

SCENIHR (Scientific Committee on Emerging and Newly Identified Health Risks) (2009) Risk Assessment of Products of Nanotechnologies; 71 pp.; European Commission Health and Consumer Protection Directorate- General, Directorate C - Public Health and Risk Assessment: Brussels, BE. Available at: http://ec.europa.eu/health/ph_risk/committees/04_scenihr/docs/scenihr_o_023.pdf (Accessed September 7, 2016)

Som C, Nowack B, Krug HF, Wick P (2013) Toward the development of decision supporting tools that can be used for safe production and use of nanomaterials. Acc Chem Res 46:20863-20872.

Stone V, Hankin S, Aitken R, Aschberger K, Baun A, Christensen F, Fernandes T, Hansen SF, Hartmann NB, Hutchinson G, Johnston H, Micheletti C, Peters S, Ross B, Sokull-Kluettgen B, Stark D, Tran L (2010a) Engineered Nanoparticles: Review of Health and Environmental Safety (ENRHES); ENRHES EU FP 7 project, final report, 2010. Available at: http://www.nanowerk.com/nanotechnology/reports/reportpdf/report133.pdf (Accessed September 7, 2016)

Stone V, Nowack B, Baun A, van den Brink N, von der Kammer F, Dusinska M, Handy R,

773 US-EPA (2010) Nanomaterial Case Studies: Nanoscale Titanium Dioxide in Water Treatment and in Topical Sunscreen. EPA/600/R-09/057F;US-EPA: Research Triangle Park, NC, USA. 
Laurent A., Harkema J., Andersen E. W., Owsianiak M., Vea E. B., Jolliet O., 2017. Human health no-effect levels of $\mathrm{TiO}_{2}$ nanoparticles as a function of their primary size. Journal of Nanoparticle Research 19, 130.

DOI: $10.1007 / \mathrm{s} 11051-017-3816-8$.

776 Vermeire T, Stevenson H, Pieters MN, Rennen M, Slob W, Hakkert BC (1999) Assessment

777 factors for human health risk assessment: a discussion paper. Crit Rev Toxicol 29:439-490.

778 Vermeire T, Pieters M, Rennen, M, Bos, P (2001) Probabilistic assessment factors for human

779 health risk assessment - A practical guide. RIVM report 601516 005, TNO report V3489.

$780 \quad$ National Institute of Public Health and the Environment: Bilthoven, NL.

781 Walser T, Demou E, Lang DJ, Hellweg S (2011) Prospective environmental life cycle

782 assessment of nanosilver T-shirts. Environ Sci Technol 45:4570-4578.

783 Wang Q, Yang Z, Yang Y, Long C, Li H (2014) A bibliometric analysis of research on the risk

784 of engineering nanomaterials during 1999-2012. Sci Total Environ 473:483-489.

785 Warheit DB (2013) How to measure hazards/risks following exposures to nanoscale or pigment-

786 grade titanium dioxide particles. Toxicol Lett 220:193-204.

787 Warheit DB, Brock WJ, Lee KP, Webb TR, Reed KL (2005) Comparative pulmonary toxicity

788 inhalation and Instillation studies with different $\mathrm{TiO}_{2}$ particle formulations: Impact of

789 surface treatments on particle toxicity. Toxicol Sci 88:514-524.

790 Warheit DB, Boatman R, Brown SC (2015) Developmental toxicity studies with 6 forms of

791 titanium dioxide test materials (3 pigment-different grade \& 3 nanoscale) demonstrate an

792 absence of effects in orally-exposed rats. Regul Toxicol Pharmacol 73:887-896.

793 Weir A, Westerhoff P, Fabricius L, Hristovski K, von Goetz N (2012) Titanium dioxide

794 nanoparticles in food and personal care products. Environ Sci Technol 46:2242-2250.

795 Wiesner MR, Lowry GV, Alvarez P, Dionysiou D, Biswas P (2006) Assessing the risks of

796 manufactured nanomaterials. Environ Sci Technol 40:4336-4345.

797 Yang Y, Doudrick K, Bi X, Hristovski K, Herckes P, Westerhoff P, Kaegi R (2014)

798 Characterization of Food-Grade Titanium Dioxide: The Presence of Nanosized Particles.

799 Environ Sci Technol 48:6391-6400.

800 